\title{
Adsorption studies of toxic metals and dyes on soil colloids and their transport in natural porous media
}

\author{
R. Murali $\cdot$ C. N. Murthy $\cdot$ R. A. Sengupta
}

Received: 22 March 2014/Revised: 19 October 2014/Accepted: 17 November 2014/Published online: 5 December 2014

(C) Islamic Azad University (IAU) 2014

\begin{abstract}
Mobile colloids in soils and aquifers can act as carriers for adsorbed contaminants and thereby facilitate the transport of contaminants. In order to understand the problem, colloids isolated from soil were used as adsorbents for toxic metals such as $\mathrm{Pb}(\mathrm{II}), \mathrm{Ni}(\mathrm{II})$, $\mathrm{Cu}(\mathrm{II}), \mathrm{Cr}(\mathrm{VI})$ and dyes such as alizarin red and methylene blue. Column experiments were conducted to investigate the mobilization of in situ colloids from soil and their size distribution. Experiments were also conducted to study the transport of alizarin red dye through soil columns at different ionic strengths $(0.01$ and $0.001 \mathrm{M})$ and $\mathrm{pH}(\mathrm{pH} 7.5,9.5$ and 11.5) and toxic metals at the ionic strength of $0.001 \mathrm{M}$. The colloids showed significant adsorption toward the contaminants with the adsorption of methylene blue reaching as high as $625 \mathrm{mg} \mathrm{g}^{-1}$. The mobilized colloids had significant difference in their size distribution, and the cumulative mass curve of colloids followed a nonlinear pattern in contrast to the previously reported linear behavior on
\end{abstract}

Electronic supplementary material The online version of this article (doi:10.1007/s13762-014-0718-5) contains supplementary material, which is available to authorized users.

R. Murali

V. S. B College of Engineering Technical Campus,

Kinathukadavu, Coimbatore, India

C. N. Murthy $(\square)$

Applied Chemistry Department, Faculty of Technology and Engineering, The Maharaja Sayajirao University of Baroda, PO Box 51, Kalabhavan, Vadodara 390001, India

e-mail: chivukula_mn@yahoo.com

R. A. Sengupta

Chemical Engineering Department, Faculty of Technology and Engineering, The Maharaja Sayajirao University of Baroda, PO Box 51, Kalabhavan, Vadodara 390001, India model systems. The dye and toxic metal transport experiments suggested their sensitivity to low ionic strength influent solution, with the capacity of colloids to transport the dye and toxic metals increasing at low ionic strength and the transport of dye at high $\mathrm{pH}$. With decreasing ionic strength, the release rate coefficient of dye increased. This study represents an important step to understand colloid-associated contaminant transport in natural soils.

Keywords Adsorption - Dye contaminant - Flocculation . Ionic strength $\cdot$ Soil colloids

\section{Introduction}

It is imperative to understand the mechanisms of colloid and colloid-associated transport of contaminants in natural porous media, when addressing environmental issues (Mishurov et al. 2008). Earlier studies have described the ground water as a two-phase system in which contaminants partition between immobile solid matrix and the mobile aqueous phase. But it has been acknowledged now that colloids in the solid phase act as a third phase and are known to be mobile in subsurface environments (Aramrak et al. 2014; Gao et al. 2004; Honeyman 1999; Magal et al. 2011; McCarthy and Zachara 1989; Puls and Powell 1992; Zhang et al. 2010). Colloidal particles with diameters $<10 \mu \mathrm{m}$ in the soil include mineral fragments, oxides of $\mathrm{Fe}$ and $\mathrm{Al}$, microbes, plant decay debris and macromolecular components such as humic substances among others (Murali et al. 2012). Mobile colloids which are ubiquitous in soil waters and ground waters adsorb the dissolved contaminants and act as carriers of these contaminants in subsurface environments. This process referred to as 
"colloid-facilitated contaminant transport" assumes importance because of their ability to carry low watersoluble hydrophobic organic contaminants (Cheng and Saiers 2010).

Many studies have reported the transport of strongly sorbing contaminants such as radionuclide's, transition metals, heavy metals, pesticides and hydrophobic organics among others in a saturated soil column (Cherrey et al. 2003; Dunnivant et al. 1992; Grolimund and Borkovec 2005; Grolimund et al. 1996; Howard and Sova 1993; Magee et al. 1991; Nelson et al. 1985; Sen et al. 2002a; Vinten et al. 1983). The co-transport and desorption of metals by colloidal particles have been studied using Zn-saturated soil (Barton and Karathanasis 2003). The study involving the transport of $\mathrm{Ni}$ (II) in a kaolin-sand bed showed that the kaolin colloids facilitate the transport of $\mathrm{Ni}$ (II) owing to their increased adsorption over sand (Sen et al. 2002b). The studies on the adsorption of $\mathrm{Cu}$ (II) and $\mathrm{Ni}(\mathrm{II})$ metal ions on iron oxide, kaolin and sand material has shown that the adsorption of $\mathrm{Cu}(\mathrm{II})$ and $\mathrm{Ni}$ (II) occurs preferentially on the colloidal materials and adsorption is favored at high $\mathrm{pH}$ (Sen et al. 2002a).

The colloid-facilitated transport of $\mathrm{Pb}$ as a model contaminant has been investigated in laboratory column experiments with sodium and calcium as major cations. It has been shown that colloid release could be prevented by infiltrating the sediment column with concentrated divalent cation, $\mathrm{Ca}^{2+}$ solution, thus preventing the contaminant transport (Grolimund and Borkovec 2005). The investigations into the ability of biosolid colloids on the transport of copper, lead and zinc performed in undisturbed soil monoliths have demonstrated their role as a potential contaminant carrier and the risk of ground water contamination by dumped biosolid wastes. The enhanced mobility of colloids and contaminants with decreasing $\mathrm{pH}$ and colloid size and increased soil macroporosity has been well reported (Karathanasis et al. 2005).

A number of studies have also described the release and transport of colloidal particles from the soil column (Grolimund and Borkovec 1999, 2006; Grolimund et al. 2001; Kretzschmar et al. 1999; Roy and Dzombak 1997; Pilgrim and Huff 1983; Swartz and Gschwend 1998). These studies typically investigate the influence of solution chemistry on colloid transport in porous media. The transport of colloids is influenced by surface chemical characteristics of natural porous media, solution chemistry, size and flow velocity (Grolimund et al. 1998). The transport of colloidal particles from the surface soil to the aquifer increases the risk of contaminant transport, thereby causing the water contamination. Thus, a quantification of transport of colloidal particles through soil assumes significance, for the estimation of leaching of contaminants (Barton and Karathanasis 2003).

The mobilization of soil colloids through natural porous media entirely depends on its size with the micrometersized colloidal particles are immobilized due to gravitational settling. But colloids of nanometer size range are considered to be highly mobile in subsurface environments, though the exact size range is not known for maximum mobility (Ranville et al. 2005).

In contrast to the large number of studies on colloidal particles release in model systems, systematic investigation into the mobilization of colloids in natural porous media and quantification of colloids released from soil are rather limited. Though studies on the transport of colloids and contaminants in porous media at variable flow rate and solution chemistry are available, our knowledge of size distribution of colloids mobilized from soil and contaminant transport at constant flow rate is limited. This study is distinguished from other published works through its focus on colloid release and colloidassociated contaminant transport at constant flow conditions.

The main objective of this study was to investigate the adsorption of alizarin red and methylene blue dye and toxic metals such as $\mathrm{Pb}(\mathrm{II}), \mathrm{Ni}(\mathrm{II}), \mathrm{Cr}(\mathrm{VI})$ and $\mathrm{Cu}(\mathrm{II})$ on colloidal particles isolated from soil and to study the transport property before and after adsorption. Experiments were conducted to investigate the influence of ionic strength and $\mathrm{pH}$ on the transport of in situ colloidassociated dye and $\mathrm{Pb}(\mathrm{II}), \mathrm{Ni}(\mathrm{II}), \mathrm{Cr}(\mathrm{VI})$ and $\mathrm{Cu}(\mathrm{II})$ at constant flow rate. These chemicals were chosen because of their strong adsorption to soil colloids and because these organic dye and inorganic toxic metals represent the two different category of contaminants in the natural environments.

\section{Materials and methods}

\section{Porous medium}

Sediment samples were collected at 0.25 -m interval from the exposed late Quaternary sediment sequences dating back to $125 \mathrm{ka}$ from the Mahi River basin of Gujarat, India. Prior to collection of sediment samples, the exposed surface was scraped clean, and polythene bags were used for collecting the samples. The collected sample was thoroughly mixed to get a homogenous mixture and sieved through a 2-mm sieve. The sediment material had a silt 
loam texture with an organic carbon content and cation exchange capacity of $5.1 \mathrm{~g} \mathrm{~kg}^{-1}$ and $40 \mathrm{mmol} \mathrm{kg}^{-1}$, respectively. The organic carbon content was determined by wet oxidation method (Walkley and Black 1934) and cation exchange capacity by column technique (Cernik et al. 1994). The soil fraction was analyzed by the pipette method (Kilmer and Alexander 1949) and consisted of sand $25 \%$, silt $61 \%$ and clay $14 \%$.

A first-order colloid release rate coefficient was calculated by fitting the decline in the colloid concentration in the breakthrough curve, i.e., from maximum to minimum colloid concentration to the Eq. (1).

$C_{t}=C_{\max } e^{-K_{\mathrm{rel}} t}$

where $C_{t}$ is the colloid concentration with respect to time, $C_{\max }$ is the maximum colloid concentration in breakthrough curve and $K_{\text {rel }}$ is the first-order release rate coefficient.

\section{Contaminants}

Solution of alizarin red, methylene blue (Chemdyes corporation), chromium(VI) oxide, nickel chloride hexahydrate $\left(\mathrm{NiCl}_{2} \cdot 6 \mathrm{H}_{2} \mathrm{O}\right)$, copper(II) nitrate trihydrate $\left(\mathrm{Cu}\left(\mathrm{NO}_{3}\right)_{2} \cdot 3 \mathrm{H}_{2} \mathrm{O}\right)$ and lead(II) nitrate $\mathrm{Pb}\left(\mathrm{NO}_{3}\right)_{2}$ (Merck chemicals) were prepared and used in the experiments.

\section{Colloid separation}

Colloidal particles were separated from the sediment samples by mixing $200 \mathrm{~g}$ of sediment with $500 \mathrm{~mL}$ double distilled water in a beaker. The above mixture was stirred overnight using a mechanical stirrer. This mixture was centrifuged for about $15 \mathrm{~min}$ at $750 \mathrm{rpm}$. It has been reported that even $3.5 \mathrm{~min}$ of centrifugation at $750 \mathrm{rpm}$ is sufficient to separate the native colloid particles from soil (Barton and Karathanasis 2003). The relative centrifugal force (RCF) was calculated by using the known formula (Upadhyay et al. 1993) and is an indication of the efficiency of separation, i.e., the separation of the non-colloidal particulates. The RCF value was 25.12 and sufficiently high to separate out all suspended matter except the colloidal dimensions. The supernatant solution was separated by decantation, and the colloidal particles present in the supernatant were separated by flocculation with $0.5 \mathrm{M} \mathrm{CaCl}_{2}$ solution. These aggregated colloids were dried at room temperature $\left(30{ }^{\circ} \mathrm{C}\right)$ and used for further analysis.

\section{Characterization of colloids}

The mineralogical composition of soil colloids was determined by powder X-ray diffraction analysis (Brucker DX).
Elemental analysis of colloids was carried out by energy dispersive X-ray analysis. Size of the colloidal particles suspended in aqueous media was measured by static light scattering instrument (miniDAWN Tristar, Wyatt technology) equipped with Ga-As semiconductor laser with a operating wavelength of $690 \mathrm{~nm}$. Transmission electron microscopy (Philips, Tecnai 20) images were taken to determine the shape of colloidal particles in the suspensions. $\zeta$-potential was calculated from the ZetaSizer (Malvern).

\section{Adsorption experiments}

The structure of alizarin red and methylene blue dyes is shown in Figure S1, supporting information, and the properties are given in Table S2, supporting information. Adsorption of dyes from their aqueous solution by colloidal particles was measured by placing $50 \mathrm{~mL}$ of dye solution with a concentration range of $50-350 \mathrm{mg} \mathrm{L}^{-1}$ in contact with $20 \mathrm{mg}$ of colloidal aggregates in a series of beakers at room temperature $\left(30 \pm 2{ }^{\circ} \mathrm{C}\right)$. Samples were stirred by using magnetic stirrer with constant speed to maintain the contents completely mixed for about $6 \mathrm{~h}$. After equilibration, samples were centrifuged at 3,000 rpm for $15 \mathrm{~min}$. The concentration of the supernatant solution was measured on a UV-Visible spectrophotometer (UV 2450, Shimadzu) at the wavelength of $520 \mathrm{~nm}$ for alizarin red and $665 \mathrm{~nm}$ for methylene blue. The quantity of adsorbed dye on colloidal particles was calculated as the difference between initial concentration and concentration at equilibrium.

In the case of toxic metals, the quantity of the native colloid adsorbent was $10 \mathrm{mg}$ and the adsorbate taken was $50 \mathrm{~mL}$ with initial concentration range of $10-50 \mathrm{mg} \mathrm{L}^{-1}$. The adsorption experiments were carried out at the $\mathrm{pH}$ of 2.75 for $\mathrm{Cr}(\mathrm{VI})$ and $\mathrm{pH} 6.5$ for $\mathrm{Pb}(\mathrm{II})$, $\mathrm{Ni}(\mathrm{II}), \mathrm{Cu}(\mathrm{II})$ and dyes. The concentration of chromium was measured on a UV-Visible spectrophotometer (UV 2450, Shimadzu) at a wavelength of $372 \mathrm{~nm}$, and the remaining toxic metals were determined using an Atomic absorption spectrometer (Electronic corporation of India Ltd. AAS 4141).

\section{Column studies}

Column setup and colloid mobilization

A chromatographic glass column with an internal diameter of $4 \mathrm{~cm}$ and length $50 \mathrm{~cm}$ was used to study the transport behavior of the colloidal particles. The bottom of the column had a porous disk to contain the sediment material. After packing the column with 
sediments, the column was gently tapped with a mechanical vibrator for $5 \mathrm{~min}$ to ensure a uniform packing of the column. The average packed height of the glass column was $15 \mathrm{~cm}$. Typical pore volume was $35 \mathrm{~mL}$, whereas the porosity and bulk density were 0.18 and $1.7 \mathrm{~kg} \mathrm{~L}^{-1}$, respectively.

The colloids were mobilized from sediments with $0.001 \mathrm{M} \mathrm{NaCl}$ solution at a constant flow rate of $0.3 \mathrm{~mL} \mathrm{~min}^{-1}$, and the effluent samples were collected at different pore volumes and analyzed for colloidal concentration by drying the solution at $100{ }^{\circ} \mathrm{C}$ as reported in the literature (Kjaergaard et al. 2004). This process was continued until a constant low concentration of colloids obtained in the effluent. The size distribution of colloidal particles mobilized out from sediments of separate set of column was also determined after centrifugation, as was done previously.

\section{Transport experiments}

This alizarin red dye transport experiments were carried out with the in situ released soil colloidal particles. Briefly, after packing, the soil columns were preconditioned with about $30 \mathrm{~mL}$ of $0.5 \mathrm{M} \mathrm{NaCl}$ solution. Then, $20 \mathrm{~mL}$ of the alizarin dye solution of $50 \mathrm{mg} \mathrm{L}^{-1}$ concentration was allowed to flow through it. This step ensured that the soil column gets sorbed with the dye so that the released colloidal particles would carry the dye.

After this sorption step, columns were leached with $0.01 \mathrm{M} \mathrm{NaCl}$ and $0.001 \mathrm{M} \mathrm{NaCl}$ solution at constant flow rate of $0.3 \mathrm{~mL} \mathrm{~min}{ }^{-1}$, and the effluents were collected. The total dye concentrations (dissolved and colloid associated) were determined using a UV-Visible spectrophotometer (UV 2450, Shimadzu) at a wavelength of $520 \mathrm{~nm}$. Since the solubility of the dye in water is fixed, the total absorbance will depend only on the colloid adsorbed dye concentration. The effect of $\mathrm{pH}$ on the release of colloidal particles was investigated at different $\mathrm{pH}$ values. Saturation of soil column with dye was achieved after preconditioning it with 5 pore volume of $0.5 \mathrm{M} \mathrm{NaCl}$ solution. In these column experiments, contaminated sediments were exposed to influent solutions with ionic strength of $0.001 \mathrm{M} \mathrm{NaCl}$ of three different $\mathrm{pH}$ values of $7.5,9.5$ and 11.5. The collected effluent samples were analyzed for $\mathrm{pH}$ and total dye concentration.

In the case of toxic metals, the same procedure described above was performed with $50 \mathrm{~mL}$ of $\mathrm{Cr}(\mathrm{VI})$ having the initial concentration of $15 \mathrm{mg} \mathrm{L}^{-1}$ and $35 \mathrm{~mL}$ of other toxic metals having the concentration of $3 \mathrm{mg} \mathrm{L}^{-1}$ with the influent solution of $0.001 \mathrm{M} \mathrm{NaCl}$.

\section{Results and discussion}

\section{Colloid characterization}

TEM images showed that the colloidal particles are highly irregular in shape and are shown in Figure S3. The hexagonal-shaped particles show the presence of kaolinite mineral in the suspension (Millot 1970). From the X-ray diffraction analysis (Figure S4), primary minerals identified were quartz, calcite, kaolinite and manganite from the $2 \theta$ values of these minerals reported in the literature and confirmed that the colloidal particles were highly heterogeneous in their mineralogical composition. The elemental content of colloids is given in Table S5 and its spectra are shown in Figure S6, supporting information, which shows that $\mathrm{Si}$ and $\mathrm{Al}$ are the major elemental constituent of colloids. The $\zeta$-potential of the colloidal particles as a function of $\mathrm{pH}$ is shown in Fig. 1. The $\zeta$-potential was positive at $\mathrm{pH} 3.5$ and became more negative as $\mathrm{pH}$ increased from 7.5 to 11.5. This charge reversal increases the possibility of their transport, if sufficient amount of anions are present in subsurface environment (Bekhit et al. 2006).

\section{Adsorption experiments}

The effect of initial solution concentration on the adsorption of the dye on colloids was investigated at room temperature $\left(30 \pm 2{ }^{\circ} \mathrm{C}\right)$ with measurements made after an equilibration time of $6 \mathrm{~h}$. The amount of the dye adsorbed with change in concentration is shown in Figure S7a. It can be seen that the adsorption of dye on colloid increases with increasing dye concentration in aqueous solution and attains equilibrium. At lower concentrations, all the dye

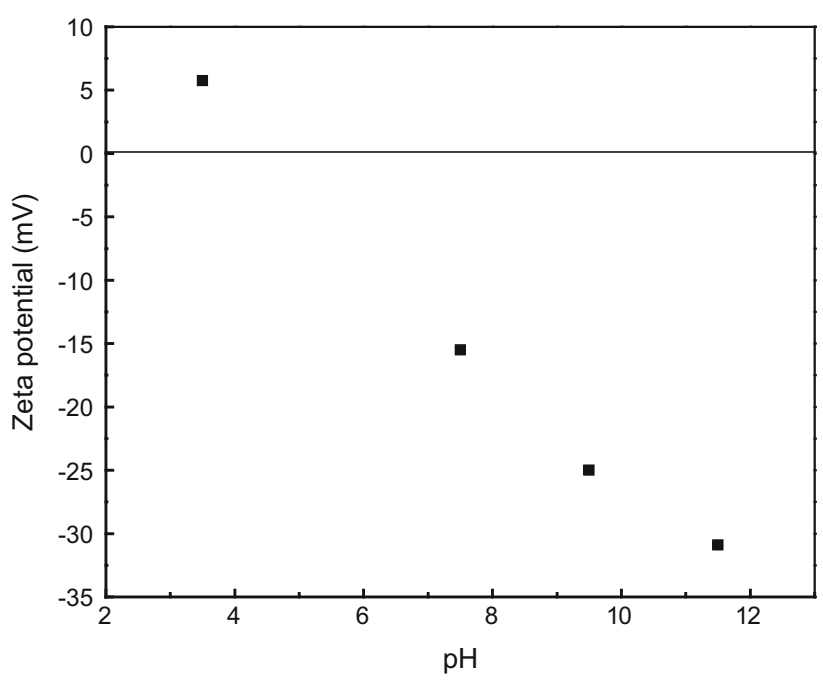

Fig. 1 Zeta potential of colloidal suspensions at different $\mathrm{pH}$ 
Fig. 2 Freundlich and Langmuir adsorption isotherm for a methylene blue (MB) and alizarin red (AR), b $\mathrm{Pb}(\mathrm{II})$ and $\mathrm{Cr}(\mathrm{VI})$ on colloids
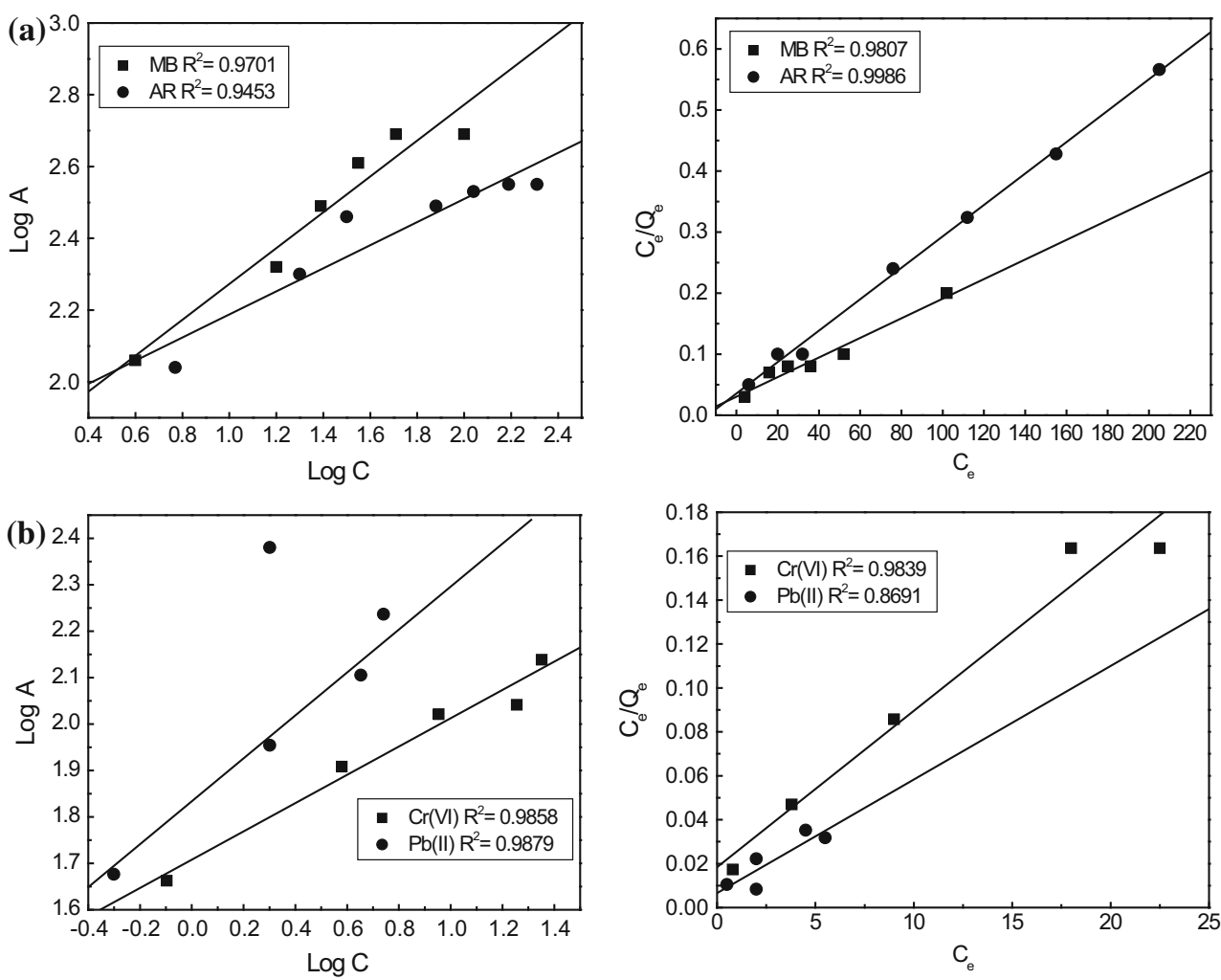

molecules present in the aqueous media are able to interact with the adsorption sites on the colloids that are followed by the slow intraparticle diffusion into the interior of the particles at higher concentrations. As the colloid is crystalline material, intraparticle diffusion occurs through the space between the lattice layers. However, the amount of adsorption of alizarin red on colloid is lower than that of methylene blue.

The experimental data were fitted to the logarithmic form of the Freundlich equation as shown in Eq. (2), and the $\log A / \log C$ plot for dyes is shown in Fig. 2 a.

$\log A=\log K_{F}+N \log C$

where $A$ is the solid phase concentration $\left(\mathrm{mg} \mathrm{g}^{-1}\right)$ and $C$ is the liquid phase concentration $\left(\mathrm{mg} \mathrm{L}^{-1}\right)$. The $K_{F}$ indicates adsorbed amount $\left[\left(\mathrm{mg} \mathrm{g}^{-1}\right) /\left(\mathrm{L} \mathrm{mg}^{-1}\right)\right]$ and $N$ indicates isotherm nonlinearity.

Langmuir isotherm can be represented by the Eq. (3) as given below

$C_{\mathrm{e}} / Q_{\mathrm{e}}=1 / Q_{0} b+C_{\mathrm{e}} / Q_{0}$

where $C_{\mathrm{e}}$ is the equilibrium concentration $\left(\mathrm{mg} \mathrm{L}^{-1}\right), Q_{\mathrm{e}}$ is the amount adsorbed at equilibrium $\left(\mathrm{mg} \mathrm{g}^{-1}\right) . b$ is a constant related to the intensity of the adsorption process, $Q_{0}$ shows the adsorption efficiency $\left(\mathrm{mg} \mathrm{g}^{-1}\right)$. The linear plots of $C_{\mathrm{e}} / Q_{\mathrm{e}}$ against $C_{\mathrm{e}}$ suggest the applicability of Langmuir adsorption isotherm. A better fit with Langmuir model is obtained for alizarin red dye with $Q_{0}$ value of $400 \mathrm{mg} \mathrm{g}^{-1}$ and the correlation coefficient being 0.9986 .

The amount of toxic metals adsorbed with change in concentration is shown in Figure $\mathrm{S} 7 \mathrm{~b}$, and the $\log A / \log$ $C$ plot for Freundlich isotherm and $C_{\mathrm{e}}$ versus $C_{\mathrm{e}} / Q_{\mathrm{e}}$ for Langmuir isotherm are shown in Fig. 2b. The Freundlich and Langmuir isotherm parameters for the adsorption of toxic metals are given in Table 1 , and the adsorbed amount of $\mathrm{Ni}$ (II) on colloid was higher and decreased in the sequence $\mathrm{Cu}(\mathrm{II}), \mathrm{Pb}(\mathrm{II})$ and $\mathrm{Cr}(\mathrm{VI})$.

The adsorption at a colloid surface is mainly a result of electrostatic binding forces that exist between ions of toxic metals to the adsorbent surface as natural colloids are negatively charged (Puls and Powell 1992). The divalent cations such as $\mathrm{Cu}(\mathrm{II}), \mathrm{Ni}(\mathrm{II})$ and $\mathrm{Pb}(\mathrm{II})$ can interact with the available deprotonated surface sites on colloids, $\equiv \mathrm{SOH}$, where $\mathrm{S}$ represents $\mathrm{Si}$ and $\mathrm{Al}$ which are the main constituent of colloids and are shown in Eqs. (4) and (5).

$\equiv \mathrm{SOH}+\mathrm{M}^{2+} \rightleftharpoons \equiv \mathrm{SOM}^{+}+\mathrm{H}^{+}$

$\equiv \mathrm{SOH}+\mathrm{M}^{2+}+\mathrm{H}_{2} \mathrm{O} \rightleftharpoons \equiv \mathrm{SOMOH}+2 \mathrm{H}^{+}$

In the case of $\mathrm{Cr}(\mathrm{VI})$ adsorption, where the $\mathrm{pH}$ of the system is 2.75 , the adsorbent surface contains a large number of protonated aluminol $\left(\mathrm{AlOH}_{2}{ }^{+}\right)$and silanol $\left(\mathrm{SiOH}_{2}{ }^{+}\right)$groups that bind electrostatically with the monomeric species of $\mathrm{Cr}(\mathrm{VI})$ which exist in solution as $\mathrm{HCrO}_{4}{ }^{-}$to cause the adsorption. 
Table 1 Freundlich and Langmuir adsorption isotherms for dyes and toxic metals

\begin{tabular}{|c|c|c|c|c|c|c|}
\hline \multirow[t]{2}{*}{ Contaminant } & \multicolumn{3}{|l|}{ Freundlich isotherm } & \multicolumn{3}{|c|}{ Langmuir isotherm } \\
\hline & $K_{F}\left(\mathrm{mg} \mathrm{g}^{-1}\right) /\left(\mathrm{L} \mathrm{mg}^{-1}\right)$ & $N$ & $R^{2}$ & $Q_{0}\left(\mathrm{mg} \mathrm{g}^{-1}\right)$ & $b\left(\mathrm{~L} \mathrm{mg}^{-1}\right)$ & $R^{2}$ \\
\hline Alizarin red & 50.1 & 0.46 & 0.9650 & 400.0 & 0.0690 & 0.9983 \\
\hline Methylene blue & 58.8 & 0.49 & 0.9701 & 625.0 & 0.053 & 0.9860 \\
\hline $\mathrm{Cr}(\mathrm{VI})$ & 50.4 & 0.30 & 0.9858 & 140.8 & 0.0178 & 0.9839 \\
\hline $\mathrm{Pb}(\mathrm{II})$ & 41.6 & 0.46 & 0.9879 & 196.0 & 0.0066 & 0.8691 \\
\hline $\mathrm{Ni}(\mathrm{II})$ & 71.6 & 0.48 & 0.9752 & 263.1 & 0.0108 & 0.8872 \\
\hline $\mathrm{Cu}(\mathrm{II})$ & 44.8 & 0.50 & 0.9839 & 222.2 & 0.0226 & 0.9724 \\
\hline
\end{tabular}

The adsorption of dyes and toxic metals is found to be relatively higher on soil colloids than other adsorbents reported in the literature, and it is given in Table 2.

\section{Colloid mobilization}

The experimental investigations involving the mobilization of colloidal particles from sediments have been carried out with $0.001 \mathrm{M} \mathrm{NaCl}$ solution. The concentration of colloids in the effluent and the mass balance of the colloids are given in Fig. 3. A significant amount of colloidal particles were found in the effluent at 0.14 pore volumes, and the breakthrough curve shows that the maxima of colloidal concentration appear at 0.42 pore volumes, and colloids kept eluting from the column to a low concentration. The increase in colloidal concentration with time is expected as the influent water soaks the soil for a longer time and so the dispersion of binding agents would be more. Despite the flow rate being constant, the decline in the concentration of colloids is caused by the finite supply of colloids, which is depleted in the progress of the experiment.

The mobilization of colloids by a change in solution chemistry depends on the alteration of forces such as double-layer attraction or repulsion, van der Waals attraction between surfaces of colloids and the aquifer grains to which they are attached (Ryan and Elimelech 1996). The change in solution chemistry causes repulsive forces between attached colloids and soil grains leading to their release and transport (Petosa et al. 2010).

The cumulative mass of colloids in the effluent turned out to be $174 \mathrm{mg}$ at 1.12 pore volumes. It can be seen from Fig. 3 that the cumulative mass curve of colloids exhibits a nonlinear pattern. It has been previously reported that the cumulative mass of colloidal particles is flow rate dependent and shows linearity at low flow rate while at high flow rate it shows nonlinearity (Jacobsen et al. 1997). Our observations indicate nonlinearity similar to that at high flow rate though our flow rate was not as high. Diffusion limited colloid mobilization
Table 2 Comparison of adsorption capacities of various adsorbents

\begin{tabular}{|c|c|c|c|}
\hline Adsorbent & Contaminant & $\begin{array}{l}\text { Adsorption } \\
\text { capacity } \\
\left(\mathrm{mg} \mathrm{g}^{-1}\right)\end{array}$ & References \\
\hline Montmorillonite & \multirow{2}{*}{$\begin{array}{l}\text { Basic green } \\
5\end{array}$} & 127.6 & \multirow{2}{*}{$\begin{array}{l}\text { Shiau and } \\
\text { Pan (2004) }\end{array}$} \\
\hline Activated clay & & 271.3 & \\
\hline \multirow{2}{*}{$\begin{array}{l}\text { Solid waste from } \\
\text { leather industry }\end{array}$} & \multirow{2}{*}{$\begin{array}{l}\text { Methylene } \\
\text { blue }\end{array}$} & 80 & \multirow{2}{*}{$\begin{array}{l}\text { Oliveira et al. } \\
\text { (2007) }\end{array}$} \\
\hline & & 163 & \\
\hline $\begin{array}{l}\text { Granular ferric } \\
\text { hydroxide }\end{array}$ & $\mathrm{Cr}(\mathrm{VI})$ & 0.78 & $\begin{array}{l}\text { Asgari et al. } \\
\text { (2008) }\end{array}$ \\
\hline Goethite & $\mathrm{Pb}(\mathrm{II})$ & 120.4 & $\begin{array}{l}\text { Mohapatra } \\
\text { et al. (2010) }\end{array}$ \\
\hline $\begin{array}{l}\text { Sawdust-activated } \\
\text { carbon }\end{array}$ & $\mathrm{Cr}(\mathrm{VI})$ & 44.0 & $\begin{array}{l}\text { Karthikeyan } \\
\text { et al. (2005) }\end{array}$ \\
\hline Soil colloids & $\begin{array}{l}\text { Methylene } \\
\text { blue }\end{array}$ & 625.0 & Present study \\
\hline Soil colloids & $\mathrm{Ni}(\mathrm{II})$ & 263.1 & Present study \\
\hline
\end{tabular}

was explained to be the cause of linearity of cumulative mass at low flow rate. In contrast, the nonlinear trend in our experiments may be due to the non-equilibrium processes and physiochemical characteristics of the soil on colloid mobilization. One of the reasons for the nonequilibrium process could also be due to the size variation of the colloidal particles leading to different adsorption capacity of the colloid. This size distribution of the colloidal particles eluted from the sediments and measured by static light scattering is given in Fig. 4 . While the initial samples had very small size range, the size of colloids after 0.7 pore volumes was high. Thereafter, the size of the colloids showed a decreasing trend and increasing again after 1.5 pore volumes. Such non-uniform and zigzag trend observed in the size distribution of colloids implies that the sediment contains particles of varying size, and these get detached and eluted out in a mixed manner. 

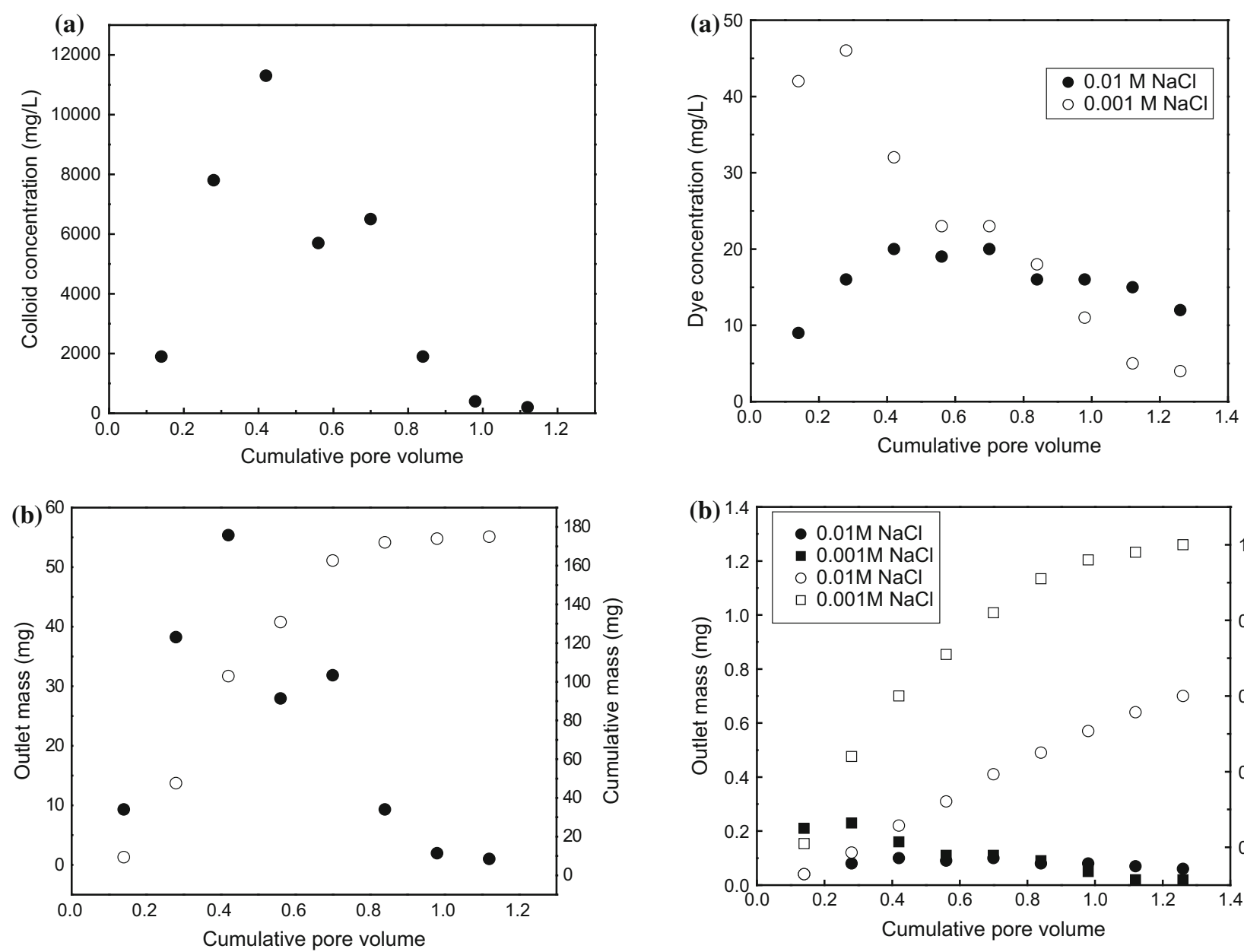

Fig. 3 Leaching of colloidal particles from soil column a colloid concentration versus cumulative pore volume. b (dark circles) Outlet mass of colloids ( $\mathrm{mg}$ ) and (open circles) cumulative mass ( $\mathrm{mg}$ ) versus cumulative pore volume

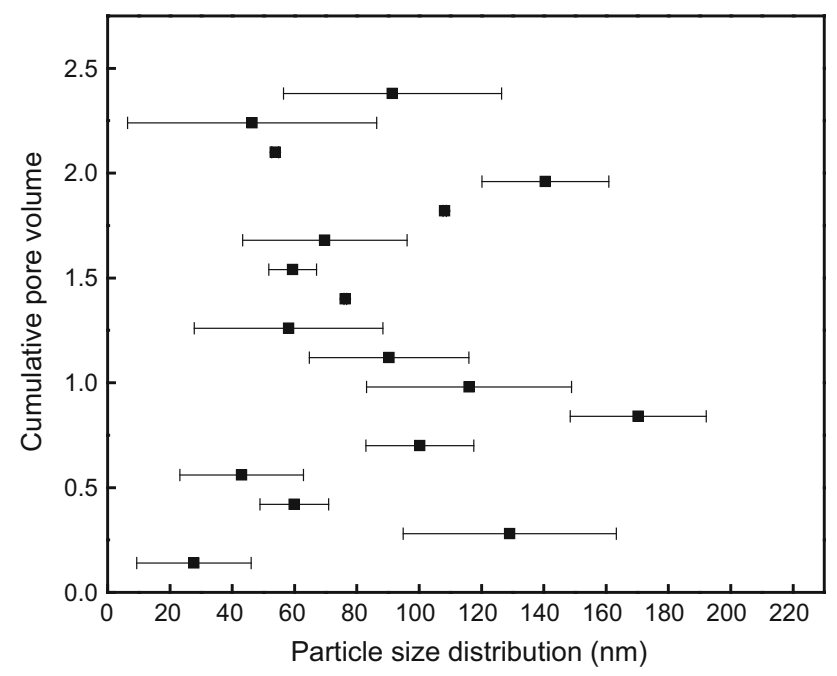

Fig. 4 Particle size distribution of colloids eluted from sediments

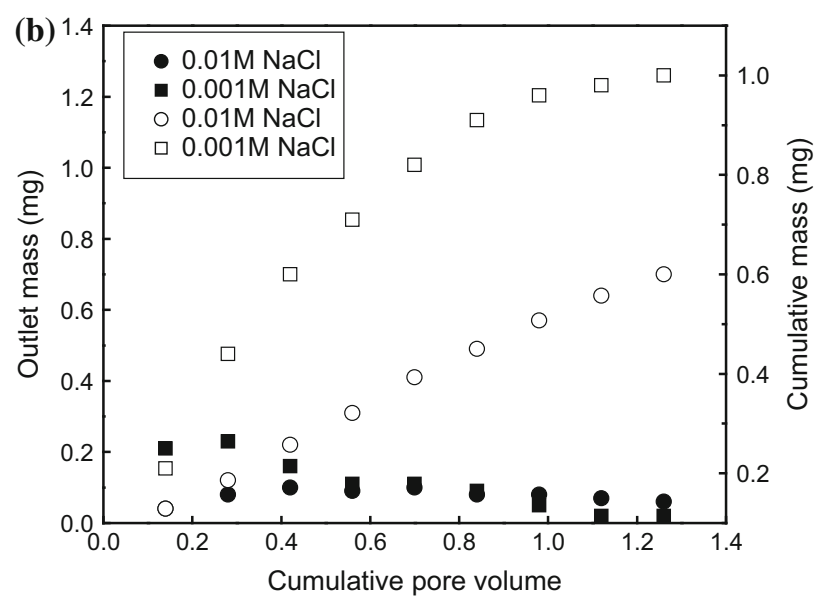

Fig. 5 Transport of the dye through the soil column. a Dye concentration at (dark circles) $0.01 \mathrm{M} \mathrm{NaCl}$, (open circles) $0.001 \mathrm{M} \mathrm{NaCl}$ versus cumulative pore volume. b Outlet mass (mg) (dark circles) and cumulative mass (mg) (open circles) versus cumulative pore volume

A first-order colloid release rate coefficient $\left(K_{\text {rel }}\right)$ determined by fitting the decrease in the colloid concentration of breakthrough curve for 15-min time interval to the Eq. (1) turned out to be $0.0451 \mathrm{~min}^{-1}$.

Dye transport experiments

The breakthrough curves of dye at the ionic strength of 0.01 and $0.001 \mathrm{M} \mathrm{NaCl}$ and the mass balance for the dye are shown in Fig. 5. The strong correlation between the effluent dye concentration and colloid concentration was observed at low ionic strength. The peak in the dye concentration of $46 \mathrm{mg} \mathrm{L}^{-1}$ was observed when the effluent colloid concentrations were $>8,000 \mathrm{mg} \mathrm{L}^{-1}$ and decreased to $4 \mathrm{mg} \mathrm{L}^{-1}$ when the colloid concentrations were $<200 \mathrm{mg} \mathrm{L}^{-1}$. These results suggest 
transport of dye when the concentrations of colloids mobilized are high.

At high ionic strength, the dye concentration peaked at 0.42 pore volumes to $20 \mathrm{mg} \mathrm{L}^{-1}$, and the majority of the dye was present in the dissolved form, due to less mobility of colloids, leading to the decreased dye concentration in the effluent as against low ionic strength conditions. As the ionic strength increased from 0.001 to $0.01 \mathrm{M}$, approximately 2.5-fold decrease in peak dye concentration and mass was observed.

The breakthrough curves clearly show that low ionic strength condition facilitates the transport of dye more and faster than high ionic strength conditions. The high ionic strength influent solution reduces the excluded area of colloidal particles through the compression of its diffuse double layers, and this causes the decrease in particle mobility, which is in agreement with previous observations (Liu et al. 1995). At the ionic strength of $0.001 \mathrm{M}$, the stability of the colloidal particles is high due to the expansion of the double layer of the colloids. This doublelayer expansion causes the colloidal particles to get easily released from the column along with the dye. The release rate coefficient of dye with respect to ionic strength is shown in Table 3. The higher release rate at $0.001 \mathrm{M}$ suggests the high mobilization of colloids from the sediment column.

The mass balance of dye transport is given in Fig. 5 . Total mass of the dye at the outlet is found to be 0.7 and $1.0 \mathrm{mg}$ for the columns leached with 0.01 and $0.001 \mathrm{M}$ influent solutions, respectively, as against the inlet mass of $1 \mathrm{mg}$. Thus, it becomes clear that the ionic strength influences the mass transport of dye through sediment-packed column and the mass of the dye retained within the column decreased as the ionic strength of the influent solution decreased.

Table 3 Release rate coefficient of colloids, alizarin red dye and toxic metals at constant flow rate

\begin{tabular}{lllll}
\hline Experiment & Contaminant & $\begin{array}{l}\text { Ionic } \\
\text { strength }\end{array}$ & $\begin{array}{l}\text { Flow rate } \\
\left(\mathrm{mL} \mathrm{min}^{-1}\right)\end{array}$ & $\begin{array}{l}\text { Release rate } \\
\text { coefficient } \\
\left(\mathrm{min}^{-1}\right)\end{array}$ \\
\hline 1 & Colloid & $0.001 \mathrm{M}$ & 0.3 & 0.0451 \\
2 & Alizarin red & $0.01 \mathrm{M}$ & 0.0048 \\
3 & Alizarin red & $0.001 \mathrm{M}$ & 0.0387 \\
4 & $\mathrm{Cr}(\mathrm{VI})$ & & 0.0046 \\
5 & $\mathrm{~Pb}(\mathrm{II})$ & & 0.0463 \\
6 & $\mathrm{Ni}(\mathrm{II})$ & & 0.0134 \\
7 & $\mathrm{Cu}(\mathrm{II})$ & & 0.0113 \\
\hline
\end{tabular}

Effect of $\mathrm{pH}$ on dye transport

The effect of $\mathrm{pH}$ on the colloid-associated transport of dye and its mass balance calculations is given in Fig. 6. The increase in dye concentration at outlet was observed with increase in the $\mathrm{pH}$ of the influent solution and is shown in Fig. 6a-c. The peak in the dye concentration was observed at different pore volumes for the experiments carried out at different $\mathrm{pH}$ values. At $\mathrm{pH} 7.5$ and 9.5, the difference in effluent dye concentration was relatively less with peak dye concentration reaching 11 and $12 \mathrm{mg} \mathrm{L}^{-1}$, respectively. As the $\mathrm{pH}$ increased to 11.5 , peak dye concentration increased to $29 \mathrm{mg} \mathrm{L}^{-1}$. The 2.5 -fold increase in peak dye concentration and mass in the effluent indicate that the colloidfacilitated transport of dye is sensitive to solution $\mathrm{pH}$. The charge of colloids becomes more negative as the $\mathrm{pH}$ increased to 11.5 as shown in Fig. 1, and this contribute to the transport of dye.

It has been observed that the surface coating of iron oxide on the quartz-based colloids shifts the point of zero charge from a pH below 3 to approximately $\mathrm{pH} 8.1$ and to a less extent for kaolinite (Hendershot and Lavkulich 1983). Thus, in our case also, this factor may have contributed to significant colloid release and dye transport above $\mathrm{pH} 8.1$. Despite the effluent concentration of dye being slightly higher at $\mathrm{pH} 9.5$ than at $\mathrm{pH} 7.5$, which is above the point of zero charge value of 8.1 , a large increase in dye concentration was observed for the $\mathrm{pH}$ of 11.5. And, these results establish the effect of $\mathrm{pH}$ on the colloid-facilitated transport dye in our experiments.

The effect of $\mathrm{pH}$ on colloid mobilization from natural sediments in laboratory columns has produced similar results, which is increase in $\mathrm{pH}$ causes increase in colloid mobilization. It has been hypothesized that the $\mathrm{pH}$ of the injection solution would have to exceed the $\mathrm{pH}_{\mathrm{pzc}}$ of grain coatings to cause significant colloid release and transport (Bunn et al. 2002; Ryan and Elimelech 1996). The pH below the $\mathrm{pH}_{\mathrm{pzc}}$, the positively charged grain coatings, would bind electrostatically with the negatively charged colloids and above the $\mathrm{pH}_{\mathrm{pzc}}$ surface charge of the coatings would be reversed resulting in electrostatic repulsion and release of colloids. The increase in dye transport at $\mathrm{pH} 11.5$ is indicative of substantial increase in colloid release due to electrostatic repulsion between colloids and grains.

With an influent solution of $\mathrm{pH} 7.5$, dye mass at the outlet was found to be $0.23 \mathrm{mg}$ as against the inlet mass of $1 \mathrm{mg}$, and for $\mathrm{pH} 9.5$ and $\mathrm{pH} \mathrm{11.5,} \mathrm{the} \mathrm{dye} \mathrm{mass} \mathrm{at} \mathrm{the}$ outlet was 0.29 and $0.92 \mathrm{mg}$, respectively. The mass of the dye at the outlet was found to be threefold higher for the 
Fig. 6 Transport of the dye contaminant at elevated $\mathrm{pH}$ values a $\mathrm{pH} 7.5, \mathbf{b} \mathrm{pH} 9.5, \mathbf{c} \mathrm{pH}$ 11.5, (dark circles) dye concentration, outlet mass (open circles) $\mathrm{pH}$, cumulative mass
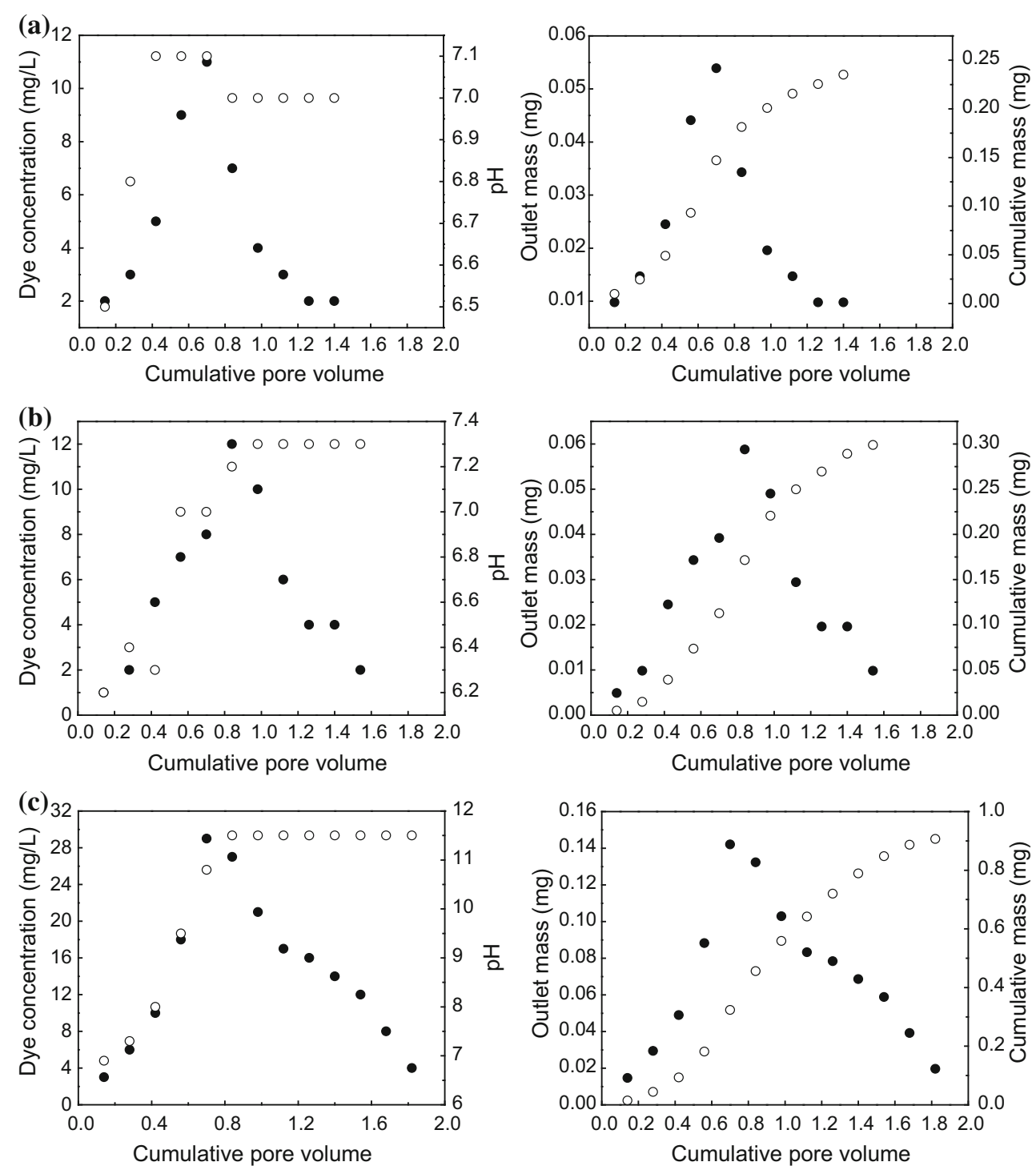

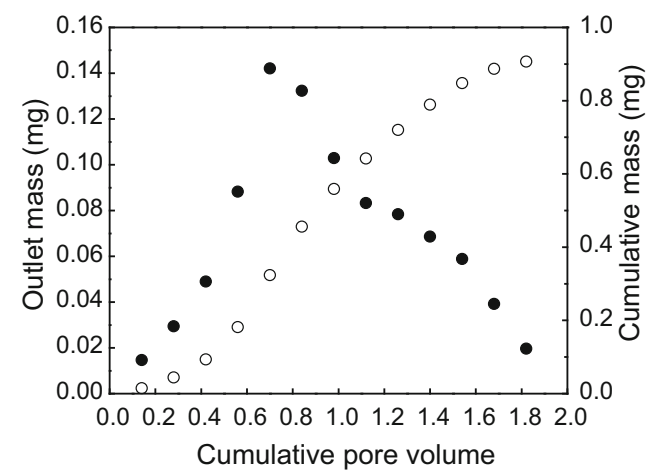

$\mathrm{pH}$ of 11.5, suggesting that the retained mass within the column decreases with increased $\mathrm{pH}$.

As shown in Fig. 6, there is a step-wise variation of $\mathrm{pH}$ of the effluent solution. For the $\mathrm{pH}$ 7.5, the effluent solution $\mathrm{pH}$ was found to be low after which the $\mathrm{pH}$ increases to 7 . Where the influent $\mathrm{pH}$ was 9.5 and 11.5 , the $\mathrm{pH}$ of the effluent was found to start at three to four $\mathrm{pH}$ units less than that of the influent solution. When the experiments were stopped, the effluent $\mathrm{pH}$ decreased to $\mathrm{pH} 7.3$ for the influent solution of $\mathrm{pH} 9.5$, but the effluent $\mathrm{pH}$ remained the same for $\mathrm{pH} 11.5$. Ion exchange is one of the possible factors for the observed decrease in $\mathrm{pH}$ of the effluent solution. The exchange of ions for $\mathrm{Al}$ in the kaolinite during the preconditioning step and subsequent hydrolysis of exchanged $\mathrm{Al}$ with the influent solution of different $\mathrm{pH}$ values causes the release of proton leading to the decrease in $\mathrm{pH}$ of effluent solution.

\section{$\mathrm{Cr}(\mathrm{VI}), \mathrm{Ni}(\mathrm{II}), \mathrm{Pb}(\mathrm{II})$ and $\mathrm{Cu}(\mathrm{II})$ transport}

The breakthrough curves for $\mathrm{Cr}(\mathrm{VI}), \mathrm{Ni}(\mathrm{II}), \mathrm{Pb}(\mathrm{II})$ and $\mathrm{Cu}$ (II) transport are shown in Fig. 7. It was recorded as a plot of $C / C_{0}$ versus pore volume where $C$ is the concentration of toxic metals in the effluent and $C_{0}$ is the initial concentration in solution. In all cases, the relative concentration in the effluent $\left(C / C_{0}\right)$ increased and then decayed with time. The effluent chromium concentration peaks at 1.1 pore volume corresponding to $40 \mathrm{~mL}$ of salt 


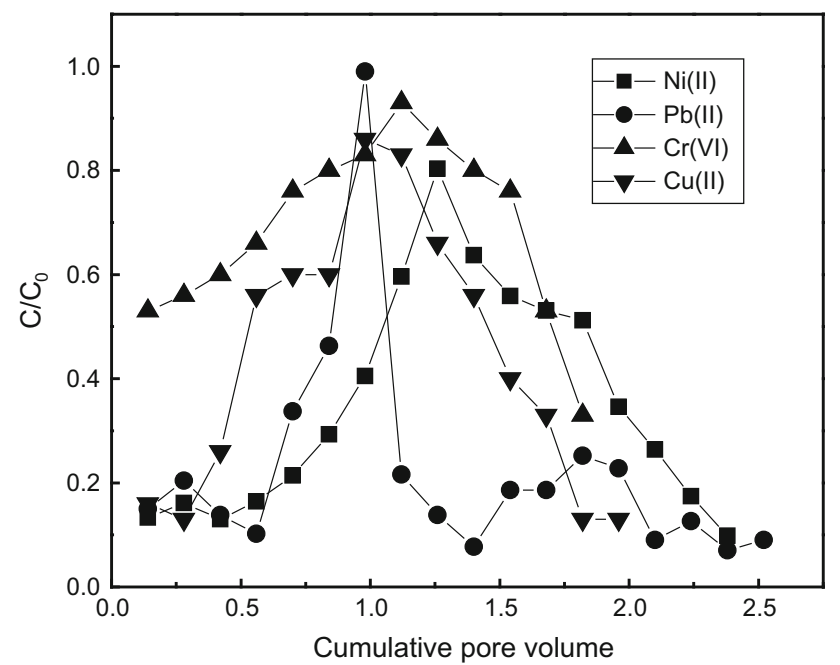

Fig. 7 Transport of $\mathrm{Ni}(\mathrm{II}), \mathrm{Pb}(\mathrm{II}), \mathrm{Cr}(\mathrm{VI})$ and $\mathrm{Cu}(\mathrm{II})$ at $0.001 \mathrm{M} \mathrm{NaCl}$

solution percolating through the bed. After 1.5 pore volumes, there is a sharp decline in the chromium concentration, and after 1.8 pore volume, the measurements were stopped, by this time $89.73 \%$ of the chromium added had eluted out from the column.

The investigations involving the transport of $\mathrm{Ni}(\mathrm{II})$, $\mathrm{Cu}$ (II) and $\mathrm{Pb}$ (II) show that the $\mathrm{Ni}$ (II) concentration attains maxima at around 1.26 pore volume, while the $\mathrm{Cu}$ (II) and $\mathrm{Pb}$ (II) peaked at 0.98 pore volume corresponding to 45 and $35 \mathrm{~mL}$ of salt solution passing though the bed, respectively. By the time the effluent concentration decreased to a low level, almost $89 \%$ of $\mathrm{Cu}(\mathrm{II}), 86 \%$ of $\mathrm{Ni}(\mathrm{II})$ and $57 \%$ of $\mathrm{Pb}$ (II) had eluted out from the column. The release rate coefficient of colloids, alizarin red dye and toxic metals is shown in Table 3. The total mass of $\mathrm{Pb}$ (II) eluted out from the column is less than other toxic metals, which increases in the sequence $\mathrm{Ni}(\mathrm{II}), \mathrm{Cu}(\mathrm{II})$ and $\mathrm{Cr}(\mathrm{VI})$. But the release rate coefficient of $\mathrm{Pb}$ (II) is high and decreases in the sequence $\mathrm{Ni}(\mathrm{II}), \mathrm{Cu}(\mathrm{II})$ and $\mathrm{Cr}(\mathrm{VI})$. This shows that release rate of $\mathrm{Pb}(\mathrm{II})$ is approximately ten times faster than $\mathrm{Cr}(\mathrm{VI})$ and 3.5 times faster than $\mathrm{Ni}$ (II) and approximately four times faster than $\mathrm{Cu}$ (II). As the effluent mass decreases, the release rate coefficient increases. Thus, it can be concluded that the transport of $\mathrm{Pb}(\mathrm{II})$ would be faster than other toxic metals in natural environments, though the mass at the outlet is less.

\section{Conclusion}

Batch experiments show that colloids have good adsorption capacity toward dyes and toxic metals. Low ionic strength enhanced the transport of dye. The significant increase in the transport of dye with increasing $\mathrm{pH}$ implies that the colloid-associated dye transport is sensitive to $\mathrm{pH}$ also. Though industrial effluents in general cannot be expected to be greater than $\mathrm{pH} 10$, improper treatment would have a major effect, and the results presented here show the transport behavior of dye in response to effluent $\mathrm{pH}$ in natural environments. Colloid mobilization experiments showed that there could be considerable leaching of native colloidal particles from the sediments during rainy season runoff. These studies can be extended to other contaminants to understand their transport through the heterogeneous soil environments.

Acknowledgments The authors gratefully acknowledge the financial assistance from Department of Science and Technology, Government of India under the grant number SR/S4/ES-21/Baroda Window/P4.

\section{References}

Aramrak S, Flury M, Harsh JB, Zollars RL (2014) Colloid mobilization and transport during capillary fringe fluctuations. Environ Sci Technol 48(13):7272-7279

Asgari AR, Vaezi F, Nasseri S, Dordelmann O, Mahvi AH, Dehghani Fard E (2008) Removal of hexavalent chromium from drinking water by granular ferric hydroxide. Iran J Environ Health Sci Eng 5:277-282

Barton CD, Karathanasis AD (2003) Colloid-enhanced desorption of zinc in soil monoliths. Int J Environ Stud 60:395-409

Bekhit HM, Hassan AE, Harris Burr R, Papelis C (2006) Experimental and numerical investigations of effects of silica colloids on transport of strontium in saturated sand columns. Environ Sci Technol 40:5402-5408

Bunn RA, Macelky RD, Ryan JN, Elimelech M (2002) Mobilization of natural colloids from an iron-oxide coated sand aquifer: effect of $\mathrm{pH}$ and ionic strength. Environ Sci Technol 36:314-322

Cernik M, Barmettler K, Grolimund D, Rohr W, Borkovec M, Sticher $\mathrm{H}$ (1994) Multicomponent transport of major cations in soil columns. J Contam Hydrol 16:319-337

Cheng T, Saiers JE (2010) Colloid-facilitated transport of cesium in vadose zone sediments: the importance of flow transients. Environ Sci Technol 44:7443-7449

Cherrey KD, Flury M, Harsh JB (2003) Nitrate and colloid transport through coarse Hanford sediments under steady state, variably saturated flow. Water Resour Res 39:1165

Dunnivant FM, Jardine PM, Taylor DL, McCarthy JF (1992) Co transport of cadmium and hexachlorobiphenyl by dissolved organic carbon through columns containing aquifer material. Environ Sci Technol 26:360-368

Gao B, Saiers JE, Ryan JN (2004) Deposition and mobilization of clay colloids in unsaturated porous media. Water Resour Res 40:1-8

Grolimund D, Borkovec M (1999) Long-term release kinetics of colloidal particles from natural porous media. Environ Sci Technol 33:4054-4060 
Grolimund D, Borkovec M (2005) Colloid-facilitated transport of strongly sorbing contaminants in natural porous media: mathematical modeling and laboratory column experiments. Environ Sci Technol 39:6378-6386

Grolimund D, Borkovec M (2006) Release of colloidal particles in natural porous media by monovalent and divalent cations. J Contam Hydrol 87:155-175

Grolimund D, Borkovec M, Barmettler K, Sticher H (1996) Colloidfacilitated transport of strongly sorbing contaminants in natural porous media: a laboratory column study. Environ Sci Technol 30:3118-3123

Grolimund D, Elimelech M, Borkovec M, Barmettler K, Kretzschmar R, Sticher H (1998) Transport of in situ mobilized colloidal particles in packed soil columns. Environ Sci Technol 32:3562-3569

Grolimund D, Barmettler K, Borkovec M (2001) Release and transport of colloidal particles in natural porous media: 2 . Experimental results and effects of ligands. Water Resour Res 37:571-582

Hendershot WH, Lavkulich LM (1983) Effect of sesquioxide coatings on surface charge of standard mineral and soil samples. Soil Sci Soc Am J 47:1252-1260

Honeyman BD (1999) Colloidal culprits in contamination. Nature 397:23-24

Howard JL, Sova JE (1993) Sequential extraction analysis of lead in Michigan roadside soils: mobilization in the vadose zone by deicing salts? J Soil Contam 2(4):361-378

Jacobsen OH, Moldrup P, Larsen C, Konnerup L, Petersen LW (1997) Particle transport in macropores of undisturbed soil columns. J Hydrol 196:185-203

Karathanasis AD, Johnson DMC, Matocha CJJ (2005) Biosolid colloid-mediated transport of copper, zinc and lead in waste amended soils. Environ Qual 34:1153-1164

Karthikeyan T, Rajgopal S, Miranda LR (2005) Cr(VI) adsorption from aqueous solution by Hevea Brasiliensis sawdust activated carbon. J Hazard Mater 13:312

Kilmer VJ, Alexander LT (1949) Methods of making mechanical analysis of soils. Soil Sci 58:15-24

Kjaergaard C, Hans Christian HB, Christian BK, Villholth KG (2004) Properties of water-dispersible colloids from macropore deposits and bulk horizons of an Agrudalf. Soil Sci Soc Am J 68:1844-1852

Kretzschmar R, Borkovec M, Grolimund D, Elimelech M (1999) Mobile subsurface colloids and their role in contaminant transport. Adv Agronom 66:121-193

Liu D, Johnson PR, Elimelech M (1995) Colloid deposition dynamics in flow through porous media: role of electrolyte concentration. Environ Sci Technol 29:2963-2973

Magal E, Weisbrod N, Yechieli Y, Walker SL, Yakirevich A (2011) Colloid transport in porous media: impact of hyper-saline solutions. Water Res 45(11):3521-3532

Magee BR, Lion LW, Lemley AT (1991) Transport of dissolved organic macromolecules and their effect on the transport of phenanthrene in porous media. Environ Sci Technol 25:323-331
McCarthy JF, Zachara JM (1989) Subsurface transport of contaminants. Environ Sci Technol 23:496-502

Millot G (1970) Geology of clays. Masson ET Cie, Paris

Mishurov M, Yakirevich A, Weisbrod N (2008) Colloid transport in a heterogeneous partially saturated sand column. Environ Sci Technol 42:1066-1071

Mohapatra M, Mohapatra L, Singh P, Anand S, Mishra BK (2010) A comparative study on $\mathrm{Pb}$ (II), $\mathrm{Cd}$ (II), $\mathrm{Cu}$ (II), $\mathrm{Co}$ (II) adsorption from single and binary aqueous solutions on additive assisted nano-structured goethite. Int J Eng Sci Technol 2:89-103

Murali R, Murthy CN, Chamyal LS (2012) Characterization of colloids in the late Quaternary sediment sequences of Mahi river basin, Gujarat, India. Curr Sci 103(10):1209-1215

Nelson DM, Penrose WR, Karttunen JO, Mehlhaff P (1985) Effects of dissolved organic carbon on the adsorption properties of plutonium in natural waters. Environ Sci Technol 19:127-131

Oliveira LCA, Goncalves M, Oliveira DQL, Guerreiro MC, Guilherme LRG, Dallago RM (2007) Solid waste from leather industry as adsorbent of organic dyes in aqueous medium. J Hazard Mater 141(1):344-347

Petosa AR, Jaisi D, Quevedo JR, Elimelch M, Tufenkji N (2010) Aggregation and deposition of engineered nanomaterials in aquatic environments: role of physiochemical interactions. Environ Sci Technol 44:6532-6549

Pilgrim DH, Huff DD (1983) Suspended sediment in rapid subsurface storm flow on a large field plot. Earth surf Process Landf 8:451-463

Puls RW, Powell RM (1992) Transport of inorganic colloids through natural aquifer material: implications for contaminant transport. Environ Sci Technol 26:614-621

Ranville JF, Chittleborough DJ, Beckett R (2005) Particle-size and element distributions of soil colloids: implications for colloid transport. Soil Sci Soc Am J 69:1173-1184

Roy SB, Dzombak DA (1997) Chemical factors influencing colloidfacilitated transport of contaminants in porous media. Environ Sci Technol 31:656-664

Ryan JN, Elimelech M (1996) Colloid mobilization and transport in ground water. Colloids Surf A 107:1-56

Sen TK, Mahajan SP, Khilar KC (2002a) Adsorption of $\mathrm{Cu}(\mathrm{II})$ and $\mathrm{Ni}(\mathrm{II})$ on iron oxide and kaolin and its importance on $\mathrm{Ni}(\mathrm{II})$ transport in porous media. Colloids Surf A Physicochem Eng Asp 211:91-102

Sen TK, Mahajan SP, Khilar KC (2002b) Colloid-associated contaminant transport in porous media: 1. Experimental studies. AIChE J 48(10):2366-2374

Shiau C, Pan C (2004) Adsorption of basic dyes from aqueous solution by various adsorbents. Sep Sci Technol 39(8): 1733-1750

Swartz CH, Gschwend PM (1998) Mechanisms controlling release of colloids to ground water in a Southeastern coastal plain aquifer sand. Environ Sci Technol 32:1779-1785

Upadhyay A, Upadhyay K, Nath N (1993) Biophysical chemistry principles and techniques. Himalaya Publishing House, Bombay 
Vinten AJA, Yaron B, Nye PH (1983) Vertical transport of pesticides into soil when adsorbed on suspended particles. J Agric Food Chem 31(3):662-664

Walkley A, Black IA (1934) An examination of the Degtjareff method for determining soil organic matter and proposed modification of the chromic acid filtration method. Soil Sci 37:29-34
Zhang W, Morales VL, Cakmak ME, Salvucci AE, Geohring LD, Hay AG, Parlange J-V, Steenhuis TS (2010) Colloid transport and retention in unsaturated porous media: effect of colloid input concentration. Environ Sci Technol 44(13):4965-4972 